\title{
Electrical stimulation test for epidural catheter placement after receiving intrathecal local anesthetic during a combined spinal-epidural technique for Cesarean delivery: confirmation of the spinal nerve root as epidural site of action
}

\author{
Malcolm Stewart, MD • Brendan Carvalho, MD • Ban C. H. Tsui, MD, MSc $₫$
}

Received: 5 October 2019/Revised: 20 October 2019/Accepted: 21 October 2019/Published online: 4 November 2019

(C) Canadian Anesthesiologists' Society 2019

\section{To the Editor,}

The epidural stimulation test (EST) has been shown to have a higher sensitivity than the local anesthetic test dose to predict adequate epidural analgesia following abdominal surgery. ${ }^{1,2}$ In obstetrical patients, this test can confirm the proper epidural catheter placement in labouring women receiving low-dose combined spinal epidural (CSE). ${ }^{3}$ Confirmation of epidural catheter placement after a full surgical spinal dose CSE for Cesarean delivery is important as epidural failure $(1.7 \%)$ is a known complication of the CSE procedure. ${ }^{4}$ We share our experience of applying an EST via the epidural catheter following full surgical spinal dose of CSE for Cesarean delivery.

A 43-yr-old gravida 5 para 2 woman at 39 weeks and two days gestation (who provided written consent for this report) presented for elective Cesarean delivery. Past obstetrical history was significant for two prior Cesarean deliveries with the previous operative report noting significant bladder adhesions to the anterior abdominal wall. Given this history and the concern for a potential prolonged surgical time, the decision was made to place a CSE. In the sitting position, a 17G, 9-cm Tuohy needle (Perifix continuous epidural tray, BBraun, Bethlehem, PA, USA) was inserted and the epidural space was identified at $5.5 \mathrm{~cm}$ depth using a loss of resistance to saline technique. A 26G, 124-mm spinal needle (GM 26124-I, Gertie Marx, Huntsville, UT, USA) was then inserted through the Tuohy, and after confirming return of cerebrospinal fluid, $1.4 \mathrm{~mL} 0.75 \%$ bupivacaine, $15 \mu \mathrm{g}$ fentanyl, and $150 \mu \mathrm{g}$

M. Stewart, MD - B. Carvalho, MD - B. C. H. Tsui, MD, $\operatorname{MSc}(\square)$.

Department of Anesthesiology, Perioperative, and Pain

Medicine, Stanford University, Palo Alto, CA, USA

e-mail: bantsui@stanford.edu morphine was injected intrathecally. Following this, a 19G epidural catheter was inserted through the Tuohy needle. The epidural catheter was then capped with an Arrow Snaplock adapter from the stimulation catheter kit (Arrow Stimucath cPNB catheter kit, Teleflex, Morrisville, NC, USA) and the epidural catheter pulled back to $10 \mathrm{~cm}$ and secured to the skin with a bio-occlusive dressing.

With the patient positioned supine with left-uterinedisplacement, normal saline $1 \mathrm{~mL}$ was injected into the epidural catheter and a nerve stimulator (Digistim 2 Plus, Neuro Technology, Houston, TX, USA) was attached to the metal flange on the Snaplock adapter. We were then able to elicit a motor response at $7.0 \mathrm{~mA}(0.1 \mathrm{msec}$ pulse width) as shown by bilateral (left $>$ right) quadriceps twitching, without patient discomfort. At the time the EST was performed, the patient reported bilateral weakness, tingling, and warmth in her lower extremities. Within five minutes, her spinal blockade was measured at the T4 dermatome level. The surgery was completed in $1.5 \mathrm{hr}$ without the need for epidural catheter injection, and it was removed at the end of the surgery.

This case shows that EST can elicit a motor response in an awake patient without discomfort after a full surgical intrathecal dose. The current threshold to elicit the motor response was comparable with the reported range of 2-10 $\mathrm{mA}$ (mean, $4.2 \mathrm{~mA}$ ) after low-dose intrathecal injection with labour CSE. ${ }^{3}$ This observation supports the notion that the site of action of the EST is primarily at the nerve roots within the epidural compartment rather than the spinal cord itself. Unrecognized epidural catheter failures after CSE procedures are an ongoing concern as a result of clinicians not being able to test or utilize the epidural catheters until after the initial spinal dose portion of the CSE has dissipated. ${ }^{5}$ This simple objective test may be valuable to confirm correct epidural catheter location at the time of 
CSE placement. This is particularly important when reassurance is desired such as in the setting of difficult CSE placement, the obese parturient, prolonged surgical time, and in labouring patients at high risk of emergent Cesarean delivery.

Conflicts of interest Dr. Tsui is the inventor of the Epidural Stimulation Test.

Funding statement None.

Editorial responsibility This submission was handled by Dr. Hilary P. Grocott, Editor-in-Chief, Canadian Journal of Anesthesia.

\section{References}

1. Balki M, Malavade A, Ye XY, Tharmaratnam U. Epidural electrical stimulation test versus local anesthetic test dose for thoracic epidural catheter placement: a prospective observational study. Can J Anesth 2019; 66: 380-7.

2. Kwofie MK, Launcelott G, Tsui BC. Determination of thoracic epidural catheter placement: electrical epidural stimulation (Tsui test) is simple, effective, and under-utilized. Can J Anesth 2019; 66: $360-4$.

3. Carvalho JC, Khemka R, Loke J, Tsui BC. Low-dose intrathecal local anesthetic does not increase the threshold current for the epidural stimulation test: a prospective observational trial of neuraxial analgesia in labouring women. Can J Anesth 2015; 62: 265-70.

4. Bloom SL, Spong CY, Weiner SJ, et al. Complications of anesthesia for cesarean delivery. Obstet Gynecol 2005; 106: 281-7.

5. Booth JM, Pan JC, Ross VH, Russell GB, Harris LC, Pan PH. Combined spinal epidural technique for labor analgesia does not delay recognition of epidural catheter failures: a single-center retrospective cohort survival analysis. Anesthesiology 2016; 125: 516-24.

Publisher's Note Springer Nature remains neutral with regard to jurisdictional claims in published maps and institutional affiliations. 